\title{
Development of Fiji English
}

\author{
Dr. Zakia Ali-Chand (iD \\ Assistant Professor, Department of Language \& Literature, School of Communication, Language and Literature, College of \\ Humanities and Education, Fiji National University, Suva, Fiji \\ $\triangle$ Corresponding Author: Dr. Zakia Ali-Chand, E-mail: zakia.chand@fnu.ac.fj
}

\section{ARTICLE INFORMATION}

Received: December 08, 2020

Accepted: February 14, 2021

Volume: 3

Issue: 2

DOI: 10.32996/jweep.2021.3.2.5

\section{KEYWORDS}

World Englishes, variety of English, Fiji English

\section{ABSTRACT}

This paper traces the development of Fiji English as a variety of English distinct from standard British English. This variety of English has been used colloquially; however, in the recent past, it has been slowly creeping in to students' academic papers. Some of its vocabulary may be seen to be quite distinct from standard British English. This paper will first discuss the classifications and models of World Englishes that have been proposed by scholars such as Kachru, Schneider, Quirk and Bolton, among others. These classifications try and explain the differences in the ways English developed its own varieties in different countries. It will then attempt to explain the stages Fiji English went through to give birth to its own distinct variety of English. Finally, it will examine some of the sources of Fiji English lexis.

\section{Introduction}

Fiji is a multi-ethnic country comprising the indigenous Fijians, as well as people of Indian and Chinese descent who are now third or fourth generation Fijian citizens, and Pacific Islanders such as Rotumans and Ocean Islanders, or Banabans, who are also Fiji citizens. In the last population census, which was taken in 2017, the total population was 884,887 (Fiji Bureau of Statistics, 2017). Fiji now has a policy of non-desegregation of data based on ethnicity. Therefore, the breakdown of ethnic groups can only be available from the population census of 2007 :

Figure 1: Population census by ethnicity 2007

\begin{tabular}{|l|l|l|l|}
\hline Total & $\begin{array}{l}\text { I-Taukei } \\
\text { (Indigenous } \\
\text { Fijians) }\end{array}$ & $\begin{array}{l}\text { Indo-Fijians } \\
\text { (Fijians of } \\
\text { Indian } \\
\text { descent) }\end{array}$ & Others \\
\hline 837,271 & 475,739 & 313,798 & 47,734 \\
\hline & $56.8 \%$ & $37.4 \%$ & $5.7 \%$ \\
\hline
\end{tabular}

Source: Fiji Bureau of Statistics, 2017

There was an increase of $5 \%$ in the overall population in the 2017 census, however, there is no current data available on the breakdown of population by ethnic groups. It is assumed that there has been little change in the overall demographics by ethnicity. The three main languages spoken in Fiji are: iTaukei or the indigenous Fijian language; Fiji Hindi, a variety of Standard Hindi from India; and Standard British English. The main language of communication, business, education and entertainment is Standard British English, by virtue of Fiji being a former British colony. On 10 $10^{\text {th }}$ October 2020 Fiji celebrated its 50 years of independence from Great Britain.

Perhaps the most common classifications of English have been to differentiate between English as a native language (ENL), English as a second language (ESL) and English as a foreign language (EFL). ENL is the primary language of countries such as Britain, USA, Australia, New Zealand and Canada. On the other hand, English is an important and often the official language of countries which are former British colonies, such as India, Nigeria, Malaysia, Fiji, or former American colonies such as American

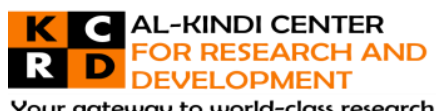

Your gateway to world-class research

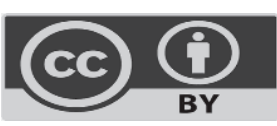

Published by Al-Kindi Center for Research and Development. Copyright (c) the author(s). This open access article is distributed under a Creative Commons Attribution (CC-BY) 4.0 license 
Samoa and the countries in the Micronesian group of islands in the Pacific. These are examples of countries where English is spoken and used as a second language. In the final classification of this model is EFL. English is used as a foreign language in countries such as China, Japan and many Middle East countries where English is taught formally in the classrooms, however, students may not have many opportunities to practice and use the language.

\subsection{Aim}

The aim of this paper is to trace the development of Fiji English in its own social and historical context. This discussion hopes to further contribute to the discussion on the sociolinguistic and stylistic study of World Englishes and their evolution as a distinct variety in their countries.

\subsection{Research methods}

Data for this study was collected from academic essays and interviews of a sample of 95 tertiary students who were enrolled in the English for Academic Purposes course in a Fijian university.

\subsection{Limitations and constraints}

While data collection from the written samples posed no major limitations, there were some constraints experienced when the participants were interviewed. Majority of the participants could not differentiate between "standard English" and "Fiji English."

\subsection{Outline of paper}

The paper will begin with a review of World Englishes and discuss the models and classifications proposed by scholars such as Kachru, Schneider, Quirk and Bolton. The discussion will then move to the application of these classifications and models to the development of Fiji English.

\section{Literature Review}

The study of the new varieties of English began as a serious topic of research in the early 1980s as a new sub-discipline of English linguistics with the publication of books (Kachru 1986, 1992, Pride 1982, cited in Schneider 2003) and scholarly journals like World Englishes (1982-). Quirk (1962, cited in Bolton, 2009, p.290) was one of the first scholars to use the term 'varieties' of English with reference to his description of how English was used worldwide. Quirk's argument was that 'English was not the prerogative or "possession" of the English...we must realize that there is no single "correct" English, and no single standard of correctness' (Quirk 1962, pp.17-18, cited in Bolton. 2009, p.290). Similar arguments were made by Halliday, McIntosh and Stevens (1964, cited in Bolton, 2009, p.290) in the era of post colonialism and they argued that even though the form of English used by the professionals in England was the only conceivable form to be used in education overseas, there was an important shift occurring which meant that English was no longer the possession of the British or the Americans as there was an emergence of varieties that could be identified with certain former colonies of Britain.

The expression World Englishes has been defined by Bolton (2009, p.240) using three approaches. In the first sense, it functions as an umbrella term to refer to global English or international English. In recent years many new terms have appeared, such as, new varieties, non-native varieties or localized varieties of English. This is the broadest sense which encompasses English as a world language. The second approach considers the term in a narrower sense which specifically refers to the 'new Englishes' spoken in the Caribbean, African and Asian societies. According to Bolton (ibid.), 'Studies of this kind focus on the areal characteristics of national or regional Englishes.' The third approach looks at the study of the English language in a wider perspective more associated with Braj B. Kachru and other scholars. According to Kachru and Smith (1985, p.210, cited in Bolton 2009, p.241), the term Englishes 'symbolizes the functional and formal variation in the language, and its international acculturation... The language now belongs to those who use it as their first language, and to those who use it as an additional language, whether in its standard form or in its localized forms.'

\subsection{The Kachruvian Circles}

The work of Braj B Kachru in the area of world Englishes (WE) is probably the greatest single contribution to the literature across a range of disciplines including applied linguistics, critical linguistics, discourse analysis and educational linguistics (Bolton 2009, p.248). Kachru (1992, cited in Bolton, 2009, p.249) summarizes the study of world Englishes in terms of 11 related and overlapping issues, which are: the spread and stratification of English; characteristics of the stratification, interactional contexts of world Englishes; implications of the spread; descriptive and prescriptive concerns; the bilingual's creativity and the literary canon; multi-canons of English; the two faces of English; nativization and Englishization; fallacies concerning users and uses; the power and politics of English; and teaching world Englishes. This model was first published in a book chapter in 1985 that came out of a conference paper presented by Kachru. In Kachru's model of the spread of English there are three concentric circles: the Inner Circle which comprises countries where English is the native or 'primary' language, similar to the ENL classification; the Outer Circle where English has spread due to colonization and is a prominent second language for business, education, entertainment, in addition to the common indigenous languages, similar to the ESL classification; and the Expanding Circle or the EFL societies where English is a foreign language and has no official function but is widely used because of its international significance in 
business and trading. In the Outer and Expanding Circles, Kachru distinguishes three varieties: firstly, the 'norm providing' varieties of the Inner Circle, which includes American and British English, and the less-preferred varieties of Australian and New Zealand English; secondly, the 'norm-developing' varieties of the Outer Circle, where the local or the 'endocentric' norm has a well-established linguistic and cultural identity, for example Singaporean, Nigerian and Indian English; and thirdly, the 'norm dependent' varieties of the Expanding Circle, for example, in Korea, Iran, Saudi Arabia, where the norms are external (or 'exocentric' such as American or British) (Bolton 2009, p.249).

Kachru went on to show that "English was spreading rapidly in non-western countries as an "additional language" and "alternative language" in multilingual societies according to the demands of modernization and technology as well as sociopolitical and sociolinguistic dynamics' (Bolton 2009, p.292). While the inner circle shared common cultural systems, the two outer circle societies shared diverse ideologies such as Hinduism, Islam, Buddhism, Communism, giving English 'a unique cultural pluralism, and a linguistic heterogeneity and diversity which are unrecorded to this extent in human history' (Kachru 2005, p.14, cited in Bolton 2009, p.292). Kachru also notes that the societies in the two outer circles are not clearly demarcated from each other. They have shared characteristics 'and the status of English in the language policies of such countries changes from time to time. What is an ESL region at one time may become an EFL region at another time or vice versa' (Kachru 1985, pp.13-14, cited in Bolton 2009, p.293)?

The first advantage of Kachru's model over the ENL/ESL/EFL model is that it makes English plural, so that there are now many Englishes. Secondly, Kachru does not suggest that any one model is linguistically superior to another. In the ENL model, the implication is that native speakers use a standard variety that is used by all countries where English is a native language and that it is innately superior to ESL and EFL. However, even in ENL countries there are many different varieties of English spoken. For example, there are differences between British and American English or differences within British or American varieties according to different regions of the countries. English has become a global language today and the idea that that there is a standard variety of English is probably incorrect. In a country where English is a second language, such as Fiji, the local variety would be more acceptable as there are more speakers of it than the standard variety. With the way English is spreading today, it is difficult to categorize any country as EFL or ESL. Countries like China, Japan and Middle East are increasingly using English, in particular, in the urban areas, as people living in the cities have greater opportunities to use English compared to the rural areas.

\subsection{Other related issues}

The issue of native-speaker ability has been a topic of discussion among second language speakers, in particular. The traditional view is that only native speakers have a proper command and understanding of the structure of English; however, this view may seem too simplistic today when the competency level of some second language speakers in countries such as India, Sri Lanka and Fiji is equal to native-speaker ability. These second language speakers have acquired competency in their mother-tongue but then have shifted to a constant use of English in their daily lives. The fluency and competency with which they use English is the same as a native speaker of English, although they would not be classified as native-speakers. Yet, in their countries and cultures they are linguistic models and users of 'New Englishes.' In Fiji authors such as Brij Lal, Ahmed Ali, Sudesh Mishra, Larry Thomas and Vijay Mishra, to name a few, are examples of what Kachru distinguishes as 'genetic nativeness from functional nativeness' (1997, pp.4-5, cited in Schneider 2003, p.238).

The issue of which variety to teach was also discussed in the 1960s by Halliday et al (Bolton 2009, p.291). It was decided that the variety must be 'used by a large number of educated people and that it is mutually intelligible with other varieties used by educated speakers from other societies' (ibid.). However, formal teaching requires formal contexts, and some sort of norm orientation but, as Schneider, questions, which and whose norms are accepted (2003, p.238).

Descriptive and theoretical linguists believe all language uses and varieties are functionally adequate while applied linguists and language teachers need advice on which norm to regard as acceptable (ibid.). According to Schneider (ibid.), there are differences between the public norms and written language on the one hand and the private spoken performance on the other. When it comes to academic and written English there are universal grammatical standards, however, it is the spoken language in which the distinct varieties of English seem to stand out.

\subsection{Schneider's dynamic model of New Englishes}

The varieties of English that have developed in postcolonial settings 'have gone through a fundamentally uniform development process, shaped by consistent sociolinguistic and language-contact conditions' (Schneider 2003, p.233). Schneider outlines five consecutive phases a speech community, such as Fiji, goes through in this process: foundation, exonormative stabilization, nativization, endonormative stabilization and differentiation (ibid.). Just as there are there are linguistic properties which cause a language to die, Schneider suggests that there are certain principles which cause the birth of a language; this birth occurs through the disintegration of a language into new- emerging local dialects (2003, p.234). Despite the huge parities between the indigenous languages and cultures that come into contact with English, Schneider claims that the emerging language or variety 
or dialect is surprisingly similar both structurally and socio-linguistically (ibid.). He attributes this to the similar contact processes that are accounted for by the theories of communication, accommodation and identity formation. Schneider proposes that New Englishes 'emerge in characteristic phases that ultimately result in dialect formation, and that the entire process is driven by identity reconstructions by the parties involved that are to some extent determined by similar parameters of the respective contact situations' (ibid.). American English would have gone through a similar development more than two hundred years ago, but is no longer considered part of the 'New Englishes' today (Schneider 2003, p.235).

As the colonies grew and expanded in the social contexts, this led to the evolution of new Englishes. The individual linguistic groups came into contact with each other and needed some new definitions of their identities and social roles amidst the backdrop of their historical roots and culture as well as in their relationships. Schneider notes, 'As these relationships changed over time, so did their identities, their images of themselves in relation to others and the world, and, in turn, their language usage as an expression of these changing identities' (Schneider 2003, p.240). These changes were not random but brought about by a certain schema of common political and economic interests, personal goals, sources of power, and choices made by the colonizers and the colonized, all sharing similar constraints and proceeding along similar paths.

Schneider proposes, firstly, that in the beginning the settlers in a foreign land regard themselves as an extension of the 'us' of their country of origin as against the 'other' of the indigenous population (p.242). Over the course of time, the former homeland becomes the 'other' while a new 'us' is developed which includes the indigenous population. Likewise, the indigenous population sees the foreigners as 'other' but over the course of time they accept the permanent residents as 'us.' 'It is through linguistic expression that much of this negotiation, definition, and expression of changing identities operate: speech patterns, that is, linguistic usage and, ultimately, emerging language varieties signify associated identity changes' (ibid.).

Schneider's five prototypical phases of evolution of a new variety of English begins with the first phase which is called foundation (Schneider 2003, p.244). This is when settlers or colonizers begin to use English on a regular basis in a country which is not an English-speaking country. Because indigenous languages are spoken in this stage, this creates a complex situation. Contact operates on two levels, independent of each other at first, involving dialect contact and language contact, respectively. This concerns both the groups' communication, internally and between each other. Thus, two different linguistic ecologies are beginning to emerge. Schneider calls them the STL or the settler strand referring to what is traditionally called the ENL and IDG or the indigenous strand referring to the ESL speech community (Schneider 2003, p.242). According to accommodation theory, forms that are widely used and shared by many will be communicatively successful and increasingly used while forms that are not understood by the majority will eventually phase out (Schneider 2003, p.244). Consequently, over time speakers adjust their pronunciation and lexical usage to facilitate understanding, a process known as "koineization" (ibid.). In this early stage there is little contact with the indigenous languages and cross-cultural communication is achieved by a small number based on their needs. According to Schneider (2003, p.245), the invading group does not bother to learn the indigenous language and very soon the indigenous group begins to develop bilingualism because their need to communicate with the immigrant is greater. Even though at this early stage the indigenous languages do not influence the English spoken by the settlers, there is one area in which lexical borrowing cannot be avoided and that is in the names of places.

The second stage in the evolution is known as exonormative stabilization. When the colonizing community, stabilizes in their new colony, English is spoken regularly in a community far away from the motherland, and soon this community develops what Schneider calls a 'distant cultural and linguistic norm orientation' which is accepted as the linguistic standard of reference (2003, p.245). While the STL community believes itself to be the representative of British culture in a foreign land, it slowly begins to adjust to the local environment and the impact of this modification is seen on the English language. The STL strand begins to move towards a new form of spoken English. They adopt the local vocabulary, at first for new objects encountered in the new territory, for example the local flora and fauna. In Fiji, for example, the ivi (Tahitian chestnut) tree in the centre of Suva, the capital city and the seat of government, has become a national heritage site as it was where local land sales took place in the early colonial days, and this terminology is now part of the local variety. Other examples include the use of bure (Fijian house), ratu (for men) and adi (for women) in the titles of the Fijians from a chiefly background. (More examples of the lexis of Fiji English are discussed later in the paper). Slowly, the acquisition of significant local vocabulary develops and becomes part of the English language used in the colony, and so a trend of borrowings from the indigenous language begins.

While the STL strand is developing, the IDG strand is also expanding its bilingualism; the indigenous population is increasingly becoming bilingual through education and increased contacts with the settlers. The ability to speak the settlers' language is highly regarded and associated with a higher social status (Schneider 2003, p.246) as it will provide them with opportunities to a better education and entry into commercial ventures. The indigenous who know English belong to the local social elite group and have an added advantage within their group. This phase leads to the most important process in the evolution of the local variety called structural nativization: 
'As soon as a population group starts to shift to a new language, some transfer phenomena on the levels of phonology and structure are bound to occur; these are largely unrecorded, being restricted to spoken vernaculars in the beginning. Consequently, in this phase the earliest structural features typical of local usage emerge, if only slowly. Thomason (2001, ch. 6) lists several mechanisms by means of which contact-induced change occurs, including code switching, code alternation, passive familiarity, second-language acquisition strategies, and, most importantly in the present context, "negotiation", the case "when speakers change their language (A) to approximate what they believe to be the patterns of another language or dialect (B)" (142)-clearly this is what happens in the emergence of New Englishes (Schneider 2003, p.246).'

This third phase of nativization is seen as the most important one as certain cultural and linguistic changes are taking place and both the groups realize that these fundamental changes are taking place for good. 'This process has immediate linguistic consequences; for the drastically increased ranges of communication between the parties involved now makes language use a major practical issue and an expression of new identity. Kachru confirms: The "acts of identity" ... are not only a matter of perception, but they have formal realization in lexicalization, in syntax, and in discourse, styles, and genres" (Prendergast 1998, p.227, cited in Schneider 2003, p.247). The STL strand now slowly cuts off the umbilical cord from the mother country and begins to gain independence, both politically and linguistically. According to Greenbaum, 'Political independence is a precursor of linguistic independence' (1996a p.11, cited in Schneider 2003, p.247). The political status of both the indigenous and settler communities is reduced to permanent residents of the same country and they both realize they need to get along with each other. Gradually, the local population goes through a process of cultural and linguistic assimilation and the acquisition of a second language. This process leads to a language shift, and in the case of Fiji, English became the language of government, business, commerce, education and entertainment after independence from Great Britain in 1970. In this early stage of nativization, most of the changes occur in the lexico-grammatical structures (Schneider 2003, p.249). There is an emergence of grammatical features of the New Englishes. 'When words co-occur increasingly frequently, locally characteristic collocations and "lexical bundles" emerge, and in the long run this may result in the development of fixed expressions or idioms' (ibid.). This grammatical nativization comprises new-word formation products. In Fiji expressions such as talanoa, meaning dialogue or discussion, or fish in lolo, which is a local way of cooking fish in coconut cream, have become part of Fiji English.

The fourth phase in Schneider's evolution of New Englishes is called endonormative stabilization (Schneider 2003, p.249). In this stage there is a gradual adoption of an indigenous linguistic norm where the language has become stable enough to create its own standards. This stage occurs post-independence where the STL strand now aligns totally with the independent former colony and breaks away from the identity of the mother country. It is difficult at first for the STL strand as they undergo a sense of abandonment and isolation, but gradually they strengthen their new status and establish a new local identity for themselves. According to Schneider (ibid.), this new identity reconstruct gives greater prominence to the country of residence rather than its historical past. As this new identity includes the indigenous groups, the role of ethnicity and ethnic boundaries become less significant. There is now greater acceptance of the new forms of local English and the community reaches an understanding that the new local norm, distinct from the colonizers' English, 'shall be accepted as adequate also in formal usage' (Newbrook 1997, p.236, cited in Schneider 2003, p.250).

Schneider (2003, p.253) calls the final phase differentiation. Now the new nation has not only achieved political independence, but a new language variety belonging to this nation has also emerged. This is a turning point in evolution of the new language; it is the stage of 'dialect birth' (ibid.). There are now new dialects, linguistic markers, accents, lexical expressions and structural patterns which have functions endemic to the new country.

These five stages of linguistic evolution are idealized phases and every country may or may not necessarily go through it stage by stage, but may end up at stage five at some point.

The discussion will now move to how this model applies to Fiji and will trace the development of Fiji English.

\section{Development of the Fiji variety of English}

Fiji falls in the Outer Circle countries of Kachru's model, together with Cook Islands, Papua New Guinea, Tonga, Samoa and Vanuatu. Even though Fiji became a British colony in 1870, English was introduced much earlier by whalers, traders and beachcombers (Tent 2001, p.212). When the first missionaries arrived on the island of Lakemba in Fiji in 1835, they had no intention of using the English language to preach Christian doctrines (Siegel 1986, p.59). If anything, they had come prepared to teach in the Fijian language as they had learned it themselves in Tonga while waiting to board a ship to Fiji. Fijian thus became the language of education and religion for the indigenous Fijians till independence in 1970. The Wesleyan missionaries established churches and schools 'in which Fijian was the medium of proselytizing and instruction' (Tent 2001, p.212). Therefore, there was no development of Pidgin English as was seen in other Pacific islands such as Vanuatu and Solomon Islands (Siegel, 1986). As Siegel notes: 
Knowledge of the Fijian language was, however, mandatory for European government officials. According to an early policy, colonial cadets who had been in the colony for two years were required by the terms of their contracts to pass an oral and written examination in Fijian. English, however, became the language of business, education and administration in post-independent Fiji' (1986, p. 69).

The number of European residents was not very large in Fiji (Schneider 2003, p.257), so the development of the STL strand may not have been significant. On the other hand, the indenture experiences from $1879-1916$ saw the introduction of a new culture and race in Fiji. Hence, Fiji English has been influenced by two IDG strands, spoken by indigenous Fijians and immigrant Indians. The language of the indentured Indian labourers was Hindi; however, because of the different dialects that were spoken by the Indians in a new cultural setting thousands of miles away from the Indian subcontinent, their Indian Hindi language evolved into Fiji Hindi, with its own morphological and lexical differences. This was the language in which people, during the indenture years, conveyed their feelings through their songs and drama. Yet, today Fiji Hindi has not been given the status of a proper language and is seen as inappropriate for use in literature (Mangubhai and Mugler 2003). [Nevertheless, two prominent Fijian Indian writers have written a play and a novel in Fiji Hindi. A play, Adhuraa Sapnaa (Incomplete Dream), was published by Raymond Pillai in 2001 and in the same year Subramani's novel, Dauka Puraan (A Subaltern's Tale) was also published (Mangubhai and Mugler 2003)].

Fiji became independent from Great Britain on October 10, 1970, after 96 years of colonial rule. English did not have a direct impact on the non-European community in Fiji 'until the late 1920s and 1930s when it became the official language of instruction after class three' Tent $(2001$, p.213). Prior to that, Fijian was the official language of the colonial administration and British civil servants were mandated to speak Fijian. After the arrival of the indentured Indian labourers, the British civil servants were also encouraged to learn Hindi (ibid.). In the 1930s, the colonial administration handed over the responsibility for education to the New Zealand government and this saw an influx of teachers from New Zealand who were neither keen to learn the local languages nor used any other language except English. Consequently, English became the medium of instruction and began to be promoted as a lingua franca (Tent 2001, p.213).

Mufwene (2001) argues that the development of English in a colony is reflective of the type of colony it was. There were 'trade colonies;' and then as time went on some came under the control of the traders and soon became 'exploitation colonies;' and there were 'settlement colonies' (Mufwene 2001, pp.8-9). Contact in trade colonies began with European traders and the local population and this contact initiated the development of pidgin varieties. It is believed that the European traders would have been using the non-standard variety of English to communicate with the local people. The trade colonies soon became exploitation colonies and came under the administrative and political control of the European nation. Contact between the local people and the colonizers increased. In the case of Fiji, the British colonizers needed English-speaking administrators to run the affairs of the colony. These administrators were recruited from three sources: people from their own country to act in the senior positions, from other colonies such as Australia and New Zealand, and some local people who were educated and trained to take up administrative positions. In Fiji, the people of chiefly status were often trained to take up administrative positions. They were given scholarships and educated in prominent universities in Australia, New Zealand and Britain. Chiefs such as the first Prime Minister of Fiji, the late Ratu Sir Kamisese Mara and the first Governor-General, the late Ratu Sir George Cakobau, come to mind as the local people educated and trained to take up leadership positions.

Subsequently, this led to the establishment of local schools where English became the medium of instruction. In the context of Fiji, English, as with other varieties in the Outer Circle countries, developed through contact with the local languages and the 'school' languages. In settlement colonies, such as Australia and New Zealand, the settlers had little contact with the local population; therefore, there was little influence on the grammar and schemas of the English language variety that developed there.

As can be seen with the historical developments, Fiji English has been influenced by its majority speakers, indigenous Fijians and Fijian Indians (Lynch and Mugler 1999). It is said to have its origins in the part-European community of Fiji (Mangubhai and Mugler, 2003, p.384) and is currently the variety spoken by the majority of the Fiji Islanders. Geraghty (1984, cited in Mangubhai and Mugler 2003, p.384) believes that Fiji English could have originated when part-Europeans, who were descendants of the "European" or British colonizers through intermarriage with the indigenous Fijians, began to attend schools which were previously restricted to the Europeans. According to Mangubhai and Mugler (2003, p.384), "Many urban Fiji Islanders are in fact bi-dialectal in Fiji English and Standard English, particularly among those whose white-collar jobs presuppose a relatively high level of education and require at least some use of Standard English."

Fiji's phase two can be traced to the 1930s when New Zealand was given the authority to oversee the development of education in Fiji (Schneider 2003, p.257). This was the time when English was given importance as a lingua franca to unite the indigenous Fijians and the Indian indentured labourers. It resulted in a rapid spread of bilingualism in English and the IDG strands. 
At the lexical level, Fiji English has borrowed much from the Fijian and Fiji Hindi languages. In phase 3, the nativization stage, many local names of places, flora and fauna, food and cultural phenomena are clearly visible, for example, local names of the two main islands, Viti Levu and Vanua Levu, Suva Point, Serua hills and the names of other geographical locations. In the flora and fauna, the names such as yaqona (Fiji's traditional drink), ivi (Tahitian chestnut), baka tree (banyan tree), ota (sea weed), tiri (mangrove), walu (kingfish), kaikoso (shell fish) and roti or Indian bread are some borrowings which have become a common occurrence in conversations (Mangubhai and Mugler, 2003, p.385). Some words have also been borrowed from colonial English, for example, compound and archaisms such as thrice (Tent 2000, 2001, cited in Mangubhai and Mugler, 2003, p.385).

Fiji English also has certain distinct pronunciations and the accent may vary depending on the speaker's first language or other social, situational and individual factors. It has crept into the written genres and often in the language used by the journalists writing for the dailies (Mangubhai and Mugler, 2003).

Fiji can also be regarded as a "diglossic" society, where language attitudes are tied to its education system (Shameem 2004, p.168). Diglossia is a term that was first introduced in 1959 by Charles Ferguson in an article that he wrote entitled 'Diglossia.' It refers to a stable language situation which has two varieties, High $(\mathrm{H})$ and Low $(\mathrm{L})$. The High variety would be used in formal language situations, for example, in a university lecture, newspaper editorial, sermon or a speech in parliament. The Low variety would be used with instructions to servants and conversation with friends. Those who are able to use the High variety are held in high regard and seen as superior in their language abilities.

This definition was expanded in 1972 by Fishman (cited in Kumar 2001, p.181) to include genetically unrelated languages of a country which exist in $\mathrm{H}$ and $\mathrm{L}$ niches where the $\mathrm{H}$ language is used for more formal purposes and the $\mathrm{L}$ is for informal and spoken domains. The current sociolinguistic situation within Fiji could well be described as diglossic. English in Fiji has two dialects or varieties, Standard English (or British English) and Fiji English (Kumar 2001, pp. 187 - 188). Standard English is the H variety which is used in education, administration and politics and Fiji English is the $L$ variety used in more informal and spoken contexts.

Fiji English has evolved over time as the lingua franca for the many different ethnic communities who are now second, third or fourth generation citizens of Fiji. It now has its own distinct grammar, syntax and vocabulary and quite often finds its way into the written texts of students. Lynch and Mugler (1999) use the term "acrolectal" to describe the variety of English spoken and written by South Pacific learners who are educated and fluent in English. For those who are less educated and less fluent they are identified as "mesolectal" and "basilectal" depending on how fluent they are. The least fluent are categorized as "basilectal." English is now the lingua franca in Fiji primarily because of its many different ethnic communities, such as indigenous Fijians, second, third and fourth generation Indians and Chinese who came in the late 1800s and early 1900s, the former as indentured labourers and the latter as traders and merchants, Europeans and their descendants who intermarried with other communities, and other Pacific Islanders.

In all the three "lects" there are distinct features noted by Lynch and Mugler (1999). For example, among the "acrolectal" category some common deviations are in tense, nouns, prepositions and generalized question tags. Tense deviations are often identified in the omission of past tense or past participial suffixes. In the usage of nouns quite often non-count nouns would have a plural form, for example, furnitures. With prepositions there is a common occurrence of errors or incorrect forms such as can't cope up with, and discuss about. When using generalized question tags, isn't it or eh are often used incorrectly in spoken English. What constitutes an error is also task dependent. It may be an error in one context while insignificant in another. According to Lynch and Mugler (1999)

The "basilectal" category could be categorized as the one with the most common features of Fiji English. Some distinct features which are common in this category are: using verb particles as verbs, for example (i) on the light, off the light; (ii) using been as a pre-verbal tense marker, for example, He been swear at me; (iii) and using full as intensifying verb, for example, He was full dancing in front of everyone (Kelly 1975, Siegel 1989, and Tent and Mugler 1996 cited in Lynch and Mugler 1999); (iv) using plenty as a prenominal quantifier, for example, Plenty people should come and taste the grog (Siegel, 1986, p.87). These are the types of deviations that have crept into the writing of Fiji students. No specific research has been conducted yet about the distribution of these errors across the different "lects".

Fiji English has since been influenced by English varieties from Australia, New Zealand and the United States of America through television and films (Mugler, 2007, p.183). It has developed in the same way as other varieties of English but its uniqueness comes from "its rich and colourful amalgam of Fijian and Hindi expressions" (Tent 2000, p.4). According to Tent (2000, p.4):

"The lexis of Fiji English embodies much of the same type of lexical material of other post-colonial Englishes. It comprises: 'indigenous' loans (i.e. Fijian, Hindi, and Polynesian); loans from other varieties of English (e.g. Indian, Australian, American and British English); calques (mainly from Fijian); re-borrowings; hybrids (i.e. English + Fijian or 
Hindi lexical collocations and compounds); standard English lexemes that have undergone locally motivated semantic shifts; grammatical conversions; novel compounds of existing standard English lexemes; English archaisms; neologisms; and locally coined exclamations, interjections and directives."

Fiji English contains approximately 38\% loanwords from the Fijian language and 16\% from Hindi (Tent 2001, p.219). Most of the loan words have been deemed necessary because of the need to retain the names of flora, fauna, geographical locations, cultural objects and events. These include kana for 'food', koro for 'village', bula for 'hello', meke for 'dance' and exclamations such as oi lei to express amazement. The borrowings from Hindi include paisa for 'money.' Vodafone has a service called M-Paisa which is a money transfer service using mobile phone networks. Other Hindi loanwords include dhania for 'coriander leaves', baigan for 'eggplant', bhajan for 'religious songs or hymns', sari for 'Indian clothing', ganja for 'marijuana' pooja for 'prayer,' Diwali 'the Hindu festival of lights' and bhindi for 'okra.'

Calques (loan translations) derived from Fijian and Hindi lexemes and phrases are also found in Fiji English (Tent 2001, p.224). Some common calques include: always to mark the simple present tense and used with never in the same sentence, for example "I always never like to hang out my clothes on the line". This is used to emphasize or illustrate the importance the action being done. Other calques include us two (loaned from Hindi hum tum as well as Fijian keirau (Tent 2001, p.225); you people from Hindi tum log; cousin-brother or cousin-sister from Indian English which has no separate terminology for male or female cousin; and us gang which is loaned from Hindi hum log, to mean 'we.'

Some compound words have been formed in Fiji English combining Hindi and Fijian words with English. These include: beanpeanut meaning snacks of peas and peanuts; force-line meaning to force yourself on others or impose on others; full-speed meaning at a great speed; grog-dope meaning drunk with yaqona (kava, Fiji's traditional drink used in ceremonies but consumed heavily at informal social gatherings as well); one-side meaning to take someone unawares; rain-bath meaning being out in the rain to have a rain shower; six to six meaning a prostitute; and warm shoes meaning house slippers made of woolen material.

\section{Conclusion}

This study has traced the development of Fiji English as a variety of English in one of the outer circle countries of Kachru's 3circle model. The findings further contribute to the paradigm of World Englishes that there is no one "standard English" today. More specifically, the way English language has evolved in its own distinct varieties post-colonially, it has also resulted in English being pluralized into World Englishes. The local variety of Fiji English developed with the support and influence of the educational systems and mandatory English medium-instruction. While this may have led to English becoming the main language for communication, business, administration and entertainment, there was a gradual localization or "nativization" of Fiji English with some of its own calques and linguistic rules. It is unique due to its borrowings from the Fijian and Hindi languages, though loanwords and calques have come more from the Fijian language since Hindi appeared on the scene after 1879.

From a socio-historical perspective, it is clear that while the "nativization" of English may be applicable to the outer circle, there is some evidence that this was also embraced by the inner circle. As Quirk argues (cited in Bolton, 2009, p.290), English is no longer the prerogative or possession of Britain. There are more ESL and EFL speakers of English today than ENL. The evolution of the local varieties of English shows that the origins of English in England no longer have any control over its development and evolution. The English language now has many owners but its greatest contribution to world communication is that it has become the lingua franca and will likely be around for hundreds of years.

While this study has tried to trace the development of Fiji English using the paradigm of World Englishes, further studies on the varieties of English in other neighbouring Pacific Island countries where the population is homogeneously indigenous, in contrast with Fiji, would add much to the literature on varieties of English in the Pacific.

British English is still Fiji's official language; however, it continues to evolve and form its own variety, mostly colloquial, but slowly penetrating the written discourse. 


\section{References}

[1] Bolton, K. (2009). World Englishes Today. The Handbook of World Englishes, chapter 15. West Sussex: Blackwell Publishing Ltd

[2] Fiji Bureau of Statistics. (2017). https://www.fiji.gov.fj/Media-Centre/News/Fiji-Bureau-of-Statistics-Releases-2017-Census-Res

[3] Kumar, M. K. (2001). 'Diglossia and its Practice in Multilingual Fiji', International Journal of Bilingual Education and Bilingualism, 4(3). 181 196. DOI: 10.1080/13670050108667727 Retrieved from: http://dx.doi.org/10.1080/13670050108667727

[4] Mangubhai, F and Mugler, F. (2003). The language situation in Fiji. Current Issues in Language Planning, 4(3/4). 367-456. ISSN 1466-4208

[5] Mugler, F. (2007). "...and the blue bird /flju/away": Yod insertion Fiji English. In J. Siegal, J. Dominic Lynch \& D. Eades (eds.), Language description, history and development: linguistic indulgence in memory of Terry Crowley. (pp 183 - 195). Amsterdam: John Benjamins Publishing

[6] Siegel, J. (1986). Pidgin English in Fiji: A Sociolinguistic History. Pacific Studies, 9(3) 53 -106.

[7] Tent, J. (2001). A profile of the Fiji English lexis. English World Wide, 22(2). 211-241

[8] Tent, J. (2004). Ch. 16 Lexical borrowing in Fiji English. In J. Tent and P. Geraghty (eds.), Borrowing: A Pacific Perspective. (pp.307 -330). Canberra Pacific Linguistics.

[9] Mufwene, S. S. (2001). The Ecology of Language Evolution. Cambridge: Cambridge University Press.

[10] Lynch, J. and Mugler, F. (1999). English in the South Pacific. Retrieved from http://www.vanuatu.usp.ac.fj/paclangunit/English south pacific.htm

[11] Shameem, N. (2004). Language attitudes in multilingual primary schools in Fiji. Language, Culture and Curriculum, 17(2). $154-172$.

[12] Schneider, E.W. (2003). The Dynamics of New Englishes: From identity construction to dialect birth. Language, 79(2), 233-281. Retrieved from http://www.jstor.org/stable/4489419 